Journal of Computer Science 7 (2): 179-187, 2011

ISSN 1549-3636

(C) 2011 Science Publications

\title{
Determination of Flux linkage Characteristics and Inductance of a Submersible Switched Reluctance Motor using Software Tools
}

\author{
${ }^{1}$ Sundaram Maruthachalam and ${ }^{2}$ Navaneethan Palaniswamy \\ ${ }^{1}$ Department of Electrical and Electronics Engineering, PSG College of Technology, \\ Avinashi Road, Coimbatore-641 004, Tamilnadu, India \\ ${ }^{2}$ Department of Electrical and Electronics Engineering, PSG College of Technology, \\ Avinashi Road, Coimbatore-641 004
}

\begin{abstract}
Problem statement: The Switched Reluctance Motor (SRM) is an old member of the Electric Machines Family. It's simple structure, ruggedness and inexpensive manufacturing capability make it more attractive for Industrial applications. Now, the applications of switched reluctance motors in various industrial fields are tried by many engineers. However, switched reluctance motors are not used so far in submersible underwater motor for agriculture purposee. The torque developed by an SRM is dependent on the change of flux-linkage and rotor position. The flux linkage characteristic of the motor is required to make the control circuit. Since the SRM is non-linear in nature, estimation and calculation of the flux linkage characteristics is very difficult. Approach: With the flux tube method concept a simple algorithm is being developed in a MATLAB. ANSYS Software is used to determine the flux distribution at various rotor positions. Results: The aligned and unaligned flux linkage values for theoretical calculation at a current of $7 \mathrm{~A}$ is $72.7 \mathrm{mwb}$ and $13.79 \mathrm{mwb}$ respectively. With FEA simulation the obtained value is 92.73 mwb and 19.175. Conclusion: In this and, a simplified method for the determination of flux linkage characteristics of submersible SRM using MATLAB has been presented. The obtained value has been validated with the ANSYS FEM method. the calculated unaligned and aligned inductance values of a 4- phase, $3 \mathrm{hp}, 220 \mathrm{~V}$ Submersible SRM using simplified MATLAB method very much matches with the ANSYS FEM Method.
\end{abstract}

Key words: Inductance value, drive system, Finite Element (FE), rotor poles, simulation model, geometrical model, ANSYS FEM method, rotor position, Switched Reluctance Motor (SRM)

\section{INTRODUCTION}

Switched Reluctance Motor (SRM) drive system has obtained considerable attention in industry and academic research. This is mainly because of its simple structure, robust performance, low cost manufacturing, high torque density and relatively simple control and converter structure. This is due to new achievements in power electronic devices, high-speed microcontrollers and advanced control strategies. Different perspectives of SRM drives have been studied over the past two decades. These researches can be divided into two main categories, namely, magnetic design of the motor and control strategies for the converter. Switched reluctance motor drives are being used in domestic and industrial applications from power steering to washing machines to traction. They are based on their advantages over competitive motors in manufacturing, reliability and robustness as well as lifetime. Normally to pump the water from bore well and under water tank, an induction motor is used. A submersible SRM can be replacing the existing squirrel cage induction motor in these applications so as to improve the efficiency and reduce the power consumption. The flux linkage characteristic of the motor is required for predicting the torque developed by a submersible SRM. The flux-linkage being a rotor position and stator excitation dependent quantity, merely considering its values for the fully aligned and unaligned conditions of the stator and rotor poles for calculating the torque developed by the motor, will lead to erratic results. (Afjei et al., 2009) Methods for calculation of the fully aligned and unaligned inductances and flux linkages are available in (Vijayakumar et al., 2008) and (Cai et al., 2010). The Finite Element (FE) method can be used to compute the inductances at various rotor positions of the SRM (Santos et al., 2010); but this necessitates a package and more time for modeling the motor. In this and, the calculation of the phase inductances and flux-linkages ( $\mathrm{Lu}$ et al., 2009). of a submersible SRM for all the rotor positions and stator excitations using a MATLAB program are presented.

Corresponding Author: SundaramMaruthachalam, PSG College of Technology, Coimbatore-641 004, Tamilnadu, India Tel: +91-422-25727770/+91-9487018281 
Table 1: Machine Specifications

\begin{tabular}{llr}
\hline Symbol & Meaning and unit & Value \\
\hline Vac & AC input Voltage $(\mathrm{V})$ & 220.000 \\
$\mathrm{P}$ & Output power $(\mathrm{kW})$ & 2.238 \\
ip & Peak current $(\mathrm{A})$ & 15.000 \\
$\mathrm{Ns}$ & No. of Stator Poles & 8.000 \\
$\mathrm{Nr}$ & No. of Rotor Poles & 6.000 \\
$\mathrm{Q}$ & Number of phase & 4.000 \\
Dso & Stator outer diameter $(\mathrm{mm})$ & 139.000 \\
Dsi & Stator inner diameter $(\mathrm{mm})$ & 70.000 \\
Dro & Rotor outer diameter $(\mathrm{mm})$ & 69.000 \\
Dri & Rotor inner diameter $(\mathrm{mm})$ & 42.040 \\
Dsf & Shaft diameter (mm) & 26.000 \\
lg & Air gap (mm) & 0.500 \\
Lstk & Stack length (mm) & 70.000 \\
$\mathrm{Hsp}$ & Stator pole height (mm) & 21.670 \\
$\mathrm{Hrp}$ & Rotor pole height $(\mathrm{mm})$ & 13.480 \\
$\beta \mathrm{s}$ & Stator pole Arc $($ degree $)$ & 21.000 \\
$\beta \mathrm{r}$ & Rotor pole Arc (degree) & 23.000 \\
$\mathrm{C}$ & Back iron thickness (mm) & 12.820 \\
$\mathrm{dw}$ & Diameter of the winding wire $(\mathrm{mm})$ & 1.300 \\
$\mathrm{hw}$ & Maximum height of winding $(\mathrm{mm})$ & 17.670 \\
$\mathrm{Nv}$ & Layers accommodated in winding & 13.000 \\
& height (mm) & \\
$\mathrm{Nh}$ & Horizontal layers & 5.000 \\
$\mathrm{Tph}$ & Turns per phase & 96.000 \\
\hline
\end{tabular}

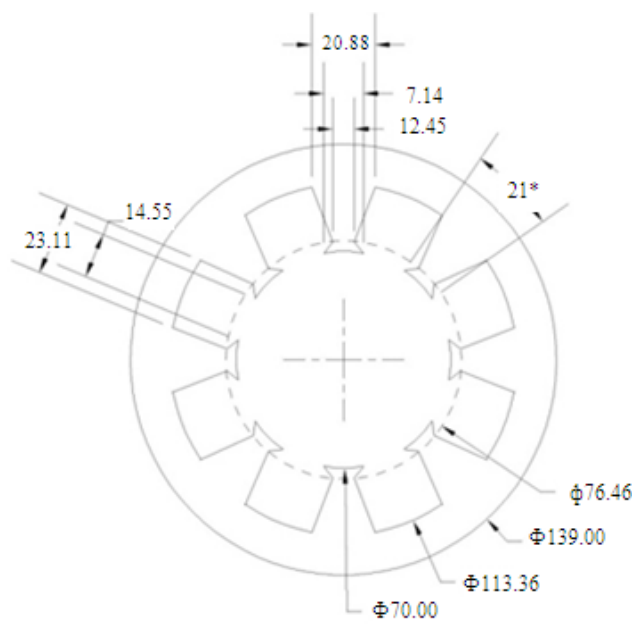

Fig. 1: Stator dimensions

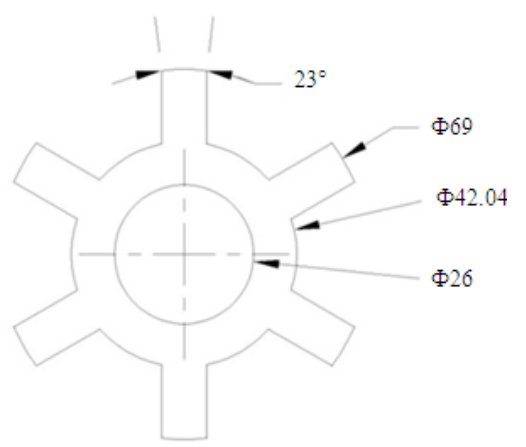

Fig. 2: Rotor dimensions
Specifications of the machine: The specifications of the submersible SRM is shown in the Table 1. The complete dimensions for stator and rotor are shown in Fig. 1-2 respectively. To mitigate the vibration effect on the stator pole, a new pole shape has been proposed as shown in Fig. 1. The proposed pole shape has a broader base and will results better flux linkage (Sundaram et al., 2009).

\section{Stator slot configurations:}

Existing slot: Table 2 shows the dimensions of the e shape is shown in Fig. 1.

The parametric simulation model: The ANSYS Workbench platform is a powerful multidomain simulation environment. Multiphysics simulation from ANSYS provides powerful simulation tools for solving industry's toughest multiphysics challenges. It also includes solutions for both direct and sequentially coupled physics problems including direct coupledfield elements (Souiyah et al., 2009).In order to analyze the submersible SRM by ANSYS Workbench, the geometrical model of the motor was plotted at first and appropriate materials are assigned to different regions (Ustun, 2009; Sundaram et al., 2009). The SRM has a complicated configuration and it is cumbersome and time-consuming to draw the geometrical model every time before simulation. This is not practical when the simulation model is supposed to be used in optimal design of the submersible SRM where the design process should be repeated frequently. Therefore, a parametric geometric model is desirable. With a reasonable approximate, the whole geometric structure of submersible SRM is generated by geometric parameters, including radius of different parts of the motor, stator and rotor pole arc lengths. The design procedure for submersible SRM is referred from (Afjei et al., 2009). The dimensional details of 4-phase, 2.28 $\mathrm{kW}, 220 \mathrm{~V}$ submersible SRM with $8 / 6$ pole configuration is shown in the Table 1. Development of SRM stator and rotor model in Pro/Engineer is shown in Fig. 3-4. Imported geometry (after assembling) is shown in Fig. 5

\section{MATERIALS AND METHODS}

The properties of materials used in the submersible SRM has been assigned in ANSYS by, defining a library of the necessary materials that composes the object (or project) being modeled. This includes thermal and mechanical properties. It is done by specifying the material used for stator and rotor as M47 Steel and field winding coil as copper alloy. 


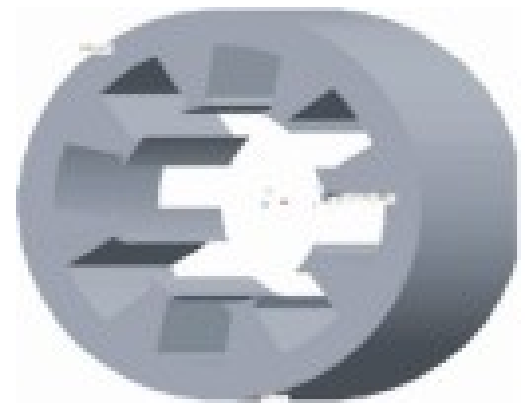

Fig. 3: Pro/Engineer stator model

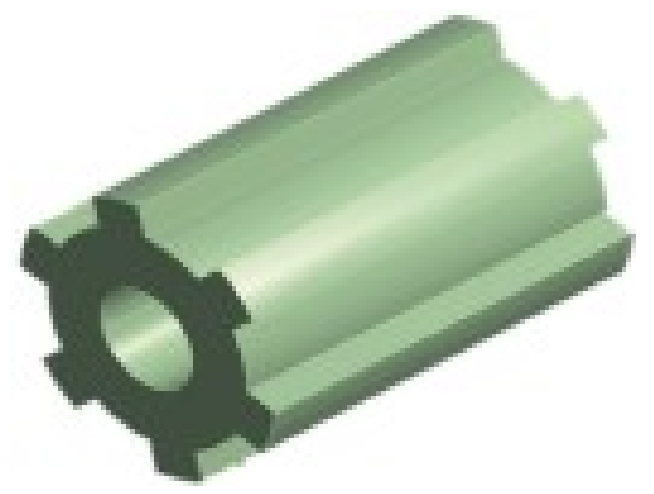

Fig. 4: Pro/Engineer rotor model

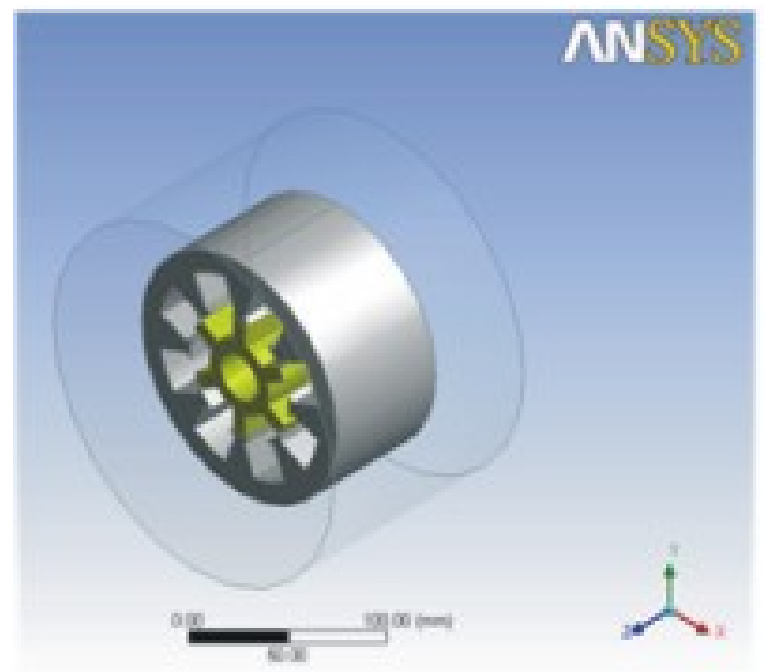

Fig. 5: Assembled model

At this point ANSYS understands the makeup of the part. Now define how the modeled system should be broken down into finite pieces. The element size of meshing can be varied relatively by specifying relevance center as coarse, medium or fine. With medium relevance, the meshed model submersible SRM is shown in Fig. 6.

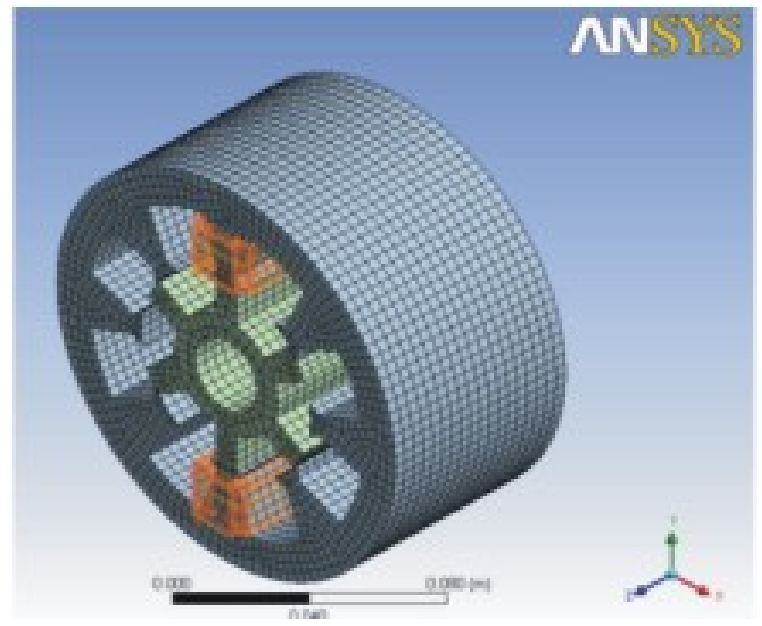

Fig. 6: Meshing of SRM-ANSYS

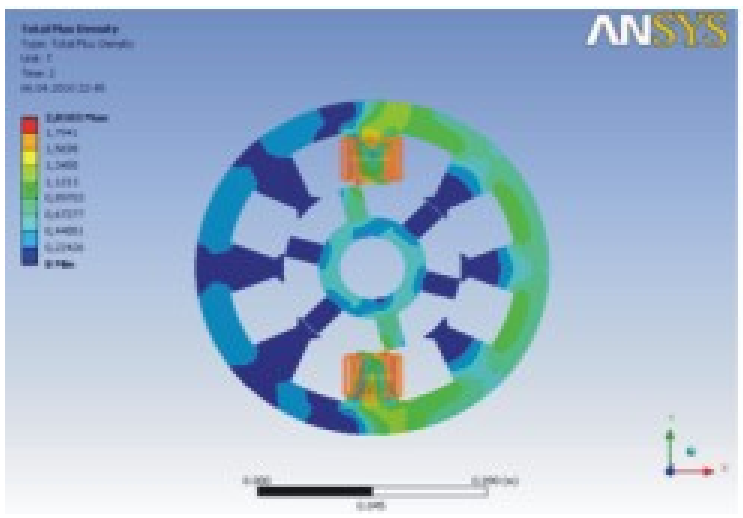

Fig. 7: Total Flux Density at $+15^{\circ}$ rotor position

Application of load and obtaining solution: Once the system is fully designed, the last task is to burden the system with constraints, such as physical loadings or boundary conditions. The load for SRM is given as the current in ampere (A) passing through the conductor winding body 1 and body 2 for specified rotor position. The current is varied from $0 \mathrm{~A}$ to $15 \mathrm{~A}$ for the rotor positions from $-45^{\circ}-45^{\circ}$ with respect to the excited pole of the stator. $0^{\circ}$ position specifies the reference as the rotor pole in exact alignment with the excited stator pole. This step specifies the type of analysis required to be performed and the parametric values to be known as the output at the end of the simulation. Since the objective is to obtain the flux linkage characteristics, magnetostatic analysis is to be performed. After the solution has been obtained, there are many ways to present ANSYS results, to be chosen from many options such as tables, graphs and contour plots. The flux linkage values, Flux and field distribution pattern are obtained in the form of graphs and contours. 


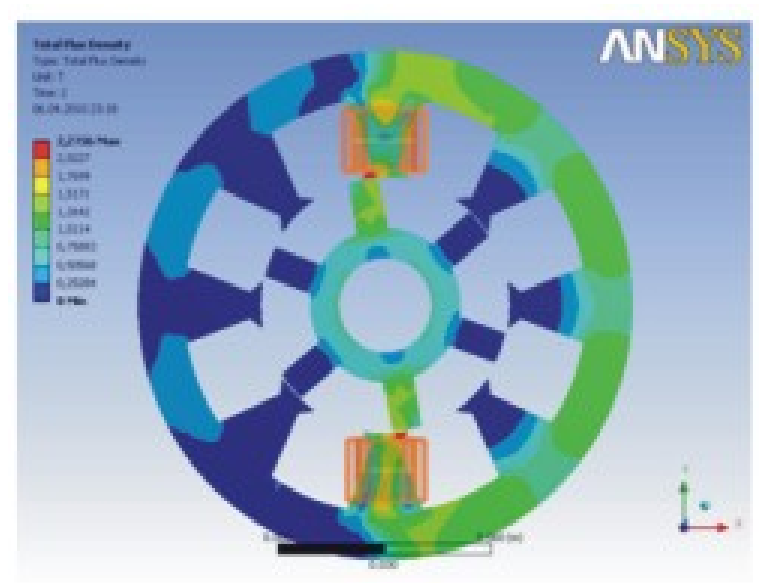

Fig. 8: Total Flux Density at $+10^{\circ}$ rotor position

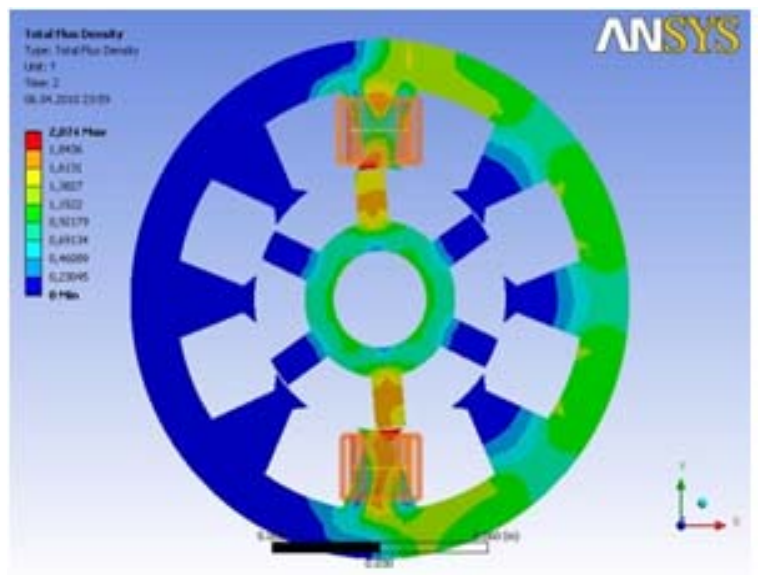

Fig. 9: Total flux density at $+5^{\circ}$ rotor position

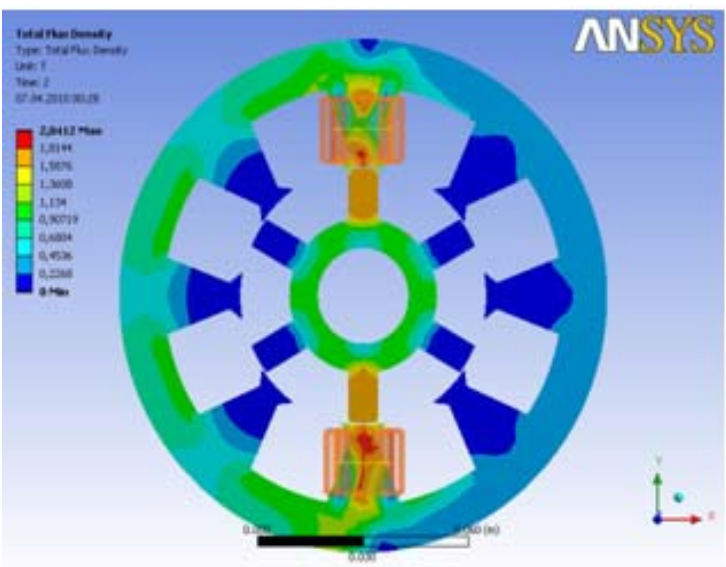

Fig. 10: Total flux density at $+0^{\circ}$ rotor position

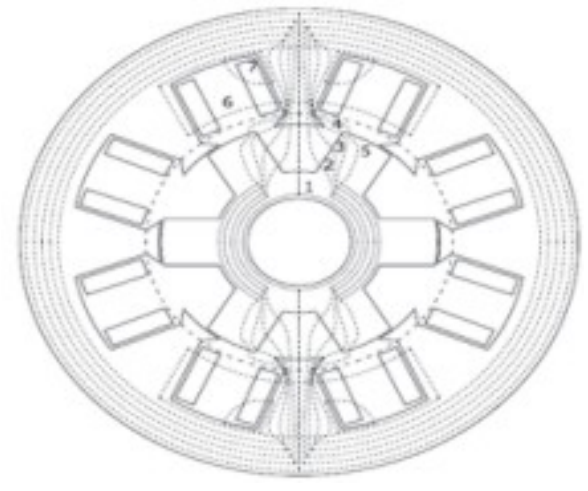

Fig. 11: Identification of 7 Flux Tubes at Unaligned Position

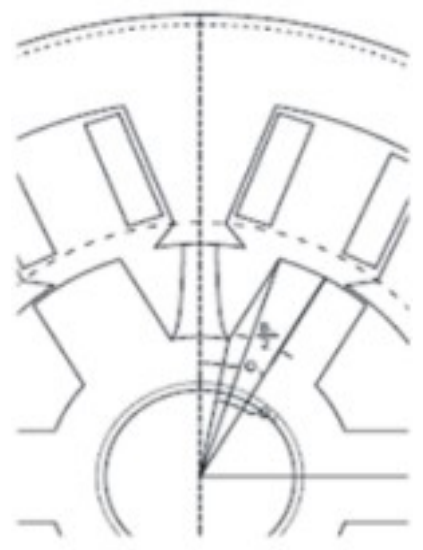

Fig. 12: Tube 1 calculations

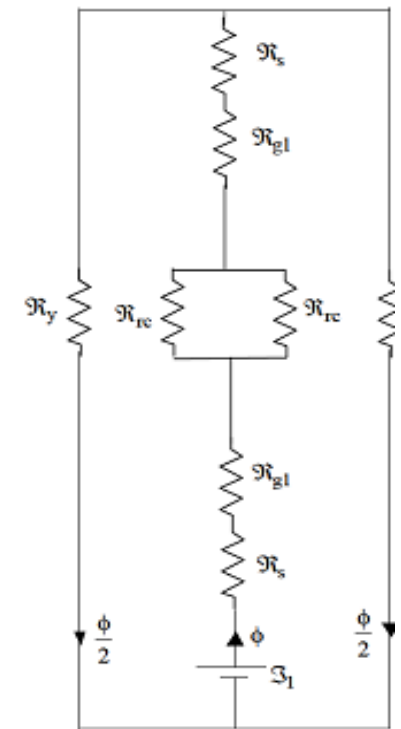

Fig. 13: Reluctance circuit for tube 1 


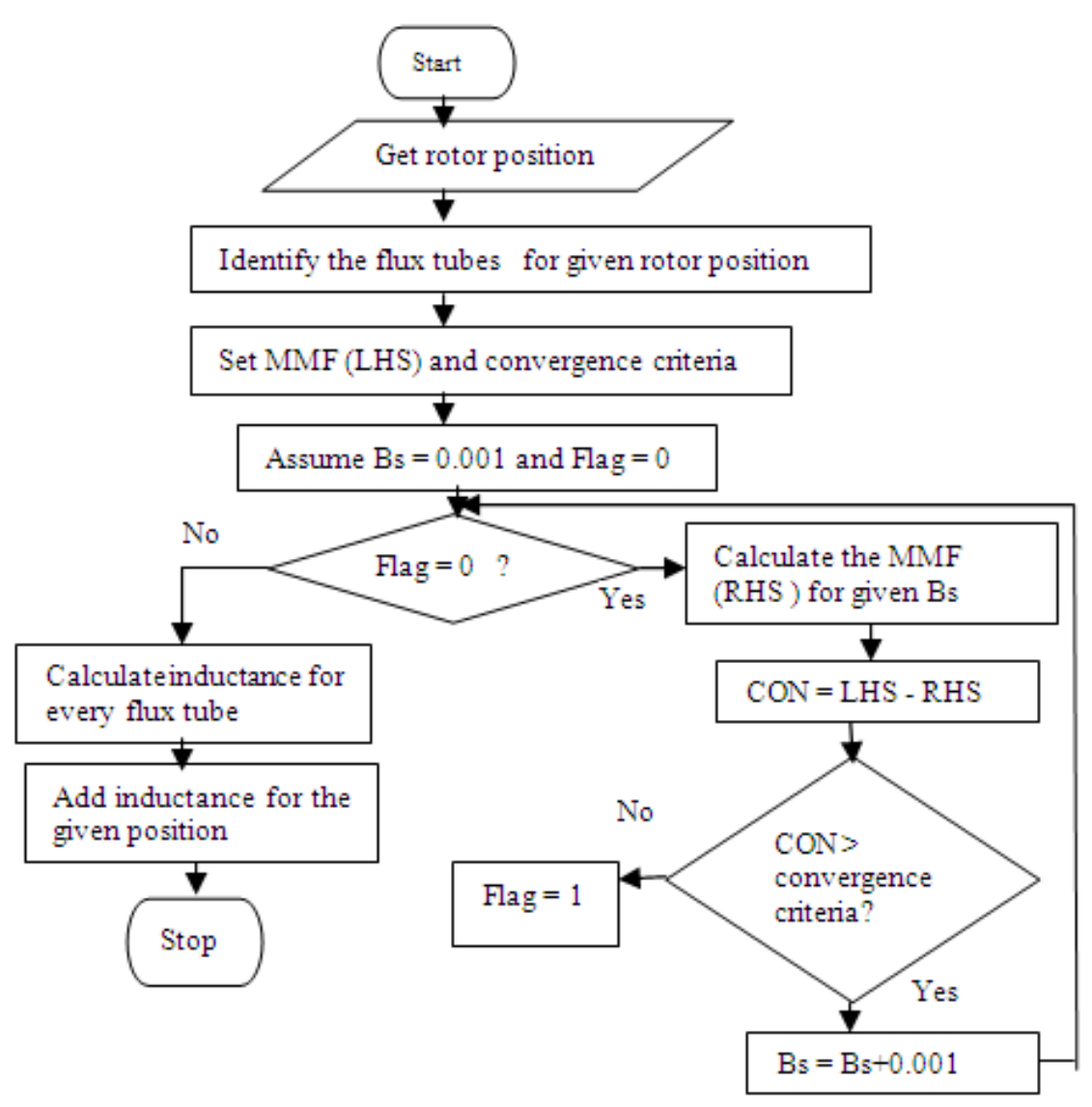

Fig. 14: Flowchart to determine inductance

Table 2: Flux linkage at aligned position

\begin{tabular}{llll}
\hline Current in A & $\begin{array}{l}\text { Flux linkage in } \\
\mathrm{m} \mathrm{Wb}\end{array}$ & $\begin{array}{l}\text { Current in } \\
\text { A }\end{array}$ & $\begin{array}{l}\text { Flux linkage } \\
\text { in m Wb }\end{array}$ \\
\hline 0 & 0 & 8 & 83.2 \\
1 & 9.9 & 9 & 93.4 \\
2 & 20.3 & 10 & 103.6 \\
3 & 30.8 & 11 & 113.4 \\
4 & 41.2 & 12 & 122.5 \\
5 & 51.6 & 13 & 129.7 \\
6 & 62.2 & 14 & 134.9 \\
7 & 72.7 & 15 & 139.3 \\
\hline
\end{tabular}

Table 3: Inductance values of various Tubes

\begin{tabular}{lll}
\hline S.No. & Tube type & Inductance $\mathrm{mH}$ \\
\hline 1 & Type 1 & 0.0027 \\
2 & Type 2 & 0.168 \\
3 & Type 3 & 0.125 \\
4 & Type 4 & 0.352 \\
5 & Type 5 & 0.156 \\
6 & Type 6 & 0.029 \\
7 & Type 7 & 0.064 \\
\hline
\end{tabular}

The contours for flux distribution for various rotor positions are given in Fig. 7-10. They represent the flux distribution for the rotor positions $+15^{\circ},+10^{\circ},+5^{\circ}$ and $0^{\circ}$, respectively, with one phase being excited.
Table 4: Flux linkage at unaligned position

\begin{tabular}{llll}
\hline Current (A) & $\begin{array}{l}\text { Flux Linkage } \\
\text { mWb }\end{array}$ & Current (A) & $\begin{array}{l}\text { Flux Linkage } \\
\mathrm{mWb}\end{array}$ \\
\hline 0 & 0 & 8 & 15.76 \\
1 & 1.97 & 9 & 17.73 \\
2 & 3.94 & 10 & 19.70 \\
3 & 5.91 & 11 & 21.67 \\
4 & 7.88 & 12 & 23.64 \\
5 & 9.85 & 13 & 25.61 \\
6 & 11.82 & 14 & 27.58 \\
7 & 13.79 & 15 & 29.55 \\
\hline
\end{tabular}

Inductance and flux linkage characteristics calculation by MATLAB: Inductance varies as the relative position between the stator and rotor varies. When a rotor pole is in complete alignment with a stator pole, it is said to be in aligned position and when the rotor pole is in exact middle of the two stator poles, it is called unaligned position. Thus, the stator and the rotor are coupled through the magnetic flux. This flux and the rotor position determine the torque of the motor. The calculation of flux linkage and inductance are shown below. 
In the submersible SRM, a linear relationship is not present between the current in the machine and the torque developed. First, the peak current $\mathrm{i}_{\mathrm{p}}=15 \mathrm{~A}$ can be split into $\mathrm{n}=15$ equal parts. Now Turns per phase $T_{\mathrm{ph}}=$ 96 turns and step current, $i_{1}=1$ :

$\tau_{1}=\mathrm{T}_{\mathrm{ph}} \times \mathrm{i}$

$=96 \times 1$

$=96 \mathrm{AT}$

Now assuming initially that flux density (Bs) = $0.001 \mathrm{~T}$, the flux densities, the AT/m and the ampereturns for all the tubes are calculated and the total AT is obtained. This procedure is repeated by incrementing the value of Bs till the error between the calculated value of ampere-turns and $\tau 1$ is negligible. The aligned inductance value for this particular current is calculated as $\mathrm{La}=9.9 \mathrm{mH}$ and the corresponding flux linkage is also obtained. The above procedure is repeated after each interval of $\alpha$; i.e., $\mathrm{i} 2=\mathrm{i} 1+\alpha$ and so on till the current reach ip, where $\alpha=1 \mathrm{~A}$. Inductance at peak current is found to be $9.3 \mathrm{mH}$. Table 2 shows the value of flux linkage at each value of current at aligned position.

Unaligned inductance: The best way to calculate the unaligned inductance is to plot the equiflux Tubes for a test machine in the unaligned rotor position and calculate the lengths of the equiflux lines in air gap and then account for the paths in the iron portions.

Sample tube calculation: The equiflux lines in the unaligned position are shown in Fig. 11. To calculate the length 11 and area A1 for Tube1, Fig. 12 is considered.

The area of the Tube at the stator pole is calculated using Eq. (2):

$\mathrm{A}_{1 \mathrm{~s}}=\beta \mathrm{s} / 4 \mathrm{D} / 2 \mathrm{~L}$

$A_{1 \mathrm{~s}}=21 / 4 \times 70 / 2 \times 70==224.5 \mathrm{~mm}^{2}$

The angle $\theta 2$ is given by Eq. (3):

$\theta 2=(\beta \mathrm{r} / 2(\mathrm{D} / 2-\mathrm{g})) /((\mathrm{D} / 2-\mathrm{g}-\mathrm{hr}))$

$\theta 2=(23 / 2(70 / 2-0.5)) /((70 / 2-0.5-13.5))$

$=0.3297 \mathrm{rad}$

The rotor pole pitch is defined in Eq. (4).

$\theta_{\mathrm{rp}}=2 \pi / \mathrm{Nr}$

$\theta_{\mathrm{rp}}=2 \pi / 6$

$=1.05 \mathrm{rad}$

The angle $\theta 3$ is calculated using Eq. (5).

$\theta_{3}=\left(\theta_{\mathrm{rp}} / 2\right)-\theta_{2}$

$\theta_{3}=(1.05 / 2)-0.3297$

$=0.195 \mathrm{rad}$

Table 5: Aligned flux linkage

\begin{tabular}{llcccc}
\hline & AlignedFlux Linkage $(\mathrm{mWb})$ & & \multicolumn{2}{c}{ Aligned Flux Linkage $(\mathrm{mWb})$} \\
Current (A) & FEA Simulation & Theoretical & Current $(A)$ & FEA Simulation & Theoretical \\
\hline 0 & 0.000 & 0.0 & 8 & 105.50 & 83.2 \\
1 & 17.680 & 9.9 & 9 & 11.29 & 93.4 \\
2 & 32.798 & 20.3 & 10 & 116.36 & 103.6 \\
3 & 47.154 & 30.8 & 11 & 120.56 & 122.4 \\
4 & 61.024 & 41.2 & 13 & 124.15 & 129.7 \\
5 & 74.377 & 51.6 & 14 & 130.01 & 134.9 \\
6 & 86.839 & 62.2 & 15 & 132.45 & 139.3 \\
7 & 97.330 & 72.7 & & 127 & \\
\hline
\end{tabular}

Table 6: Unaligned flux linkage

\begin{tabular}{lccccc}
\hline & Unaligned flux linkage $(\mathrm{mWb})$ & & \multicolumn{2}{c}{ Unaligned flux linkage $(\mathrm{mWb})$} \\
\cline { 2 - 2 }$(\mathrm{A})$ & FEA Simulation & Theoretical & Current $(\mathrm{A})$ & FEA Simulation & Theoretical \\
\hline 0 & 0.0000 & 0.00 & 8 & 21.299 & 15.76 \\
1 & 5.1488 & 1.97 & 9 & 23.410 & 17.73 \\
2 & 8.0506 & 3.94 & 10 & 25.505 & 19.70 \\
3 & 10.4280 & 5.91 & 11 & 27.583 & 21.67 \\
4 & 12.6760 & 7.88 & 12 & 29.654 & 23.64 \\
5 & 14.8670 & 9.85 & 13 & 31.713 & 25.61 \\
6 & 17.0290 & 11.82 & 15 & 33.764 & 27.58 \\
7 & 19.1750 & 13.79 & & 35.801 & 29.55 \\
\hline
\end{tabular}


The obtained aligned Flux linkage value by both FEA Simulation and Theoretical is shown in Table 5. Both the values are matching at rated current of $15 \mathrm{~A}$. The obtained Unaligned Flux linkage value by both FEA Simulation and Theoretical is shown in Table 6. Both the values are nearly equal at rated current of $15 \mathrm{~A}$.

The area of the Tube at the rotor core is calculated as in Eq. (6).

$\mathrm{A}_{1 \mathrm{r}}=2\left((\mathrm{D} / 2)-\mathrm{g}-\mathrm{h}_{\mathrm{r}}\right) \theta_{3} \mathrm{~L}$

$\mathrm{A}_{1 \mathrm{r}}=2((70 / 2)-0.5-13.5) 0.195 \times 70$

$=569.15 \mathrm{~mm}^{2}$

The average area of the air gap A1 is calculated using Eq. (7).

$\mathrm{A} 1=(\mathrm{A} 1 \mathrm{~s}+\mathrm{A} 1 \mathrm{r}) / 2$

$\mathrm{A} 1=(224.5+569.15) / 2$

$=396.8 \mathrm{~mm} 2$

The length of the air gap is given by Eq. (8).

$\mathrm{l}_{1}=(\mathrm{D} / 2)-\mathrm{g}-\mathrm{h}_{\mathrm{r}}$

$1_{1}=(70 / 2)-0.5-13.5$

$=21 \mathrm{~mm}$.

Using the B-H characteristics for the material used for the laminations, the magnetic field intensity in Ampere-turns per meter for each portion of the machine except the air-gap is obtained. The magnetic field intensities in the stator pole, stator yoke, rotor pole and rotor core are designated as $\mathrm{Hs}, \mathrm{Hy}, \mathrm{Hr}$ and $\mathrm{Hrc}$, respectively. Referring to Fig. 13, the magnetic circuit equation of Tube 1 is given in Eq. 9, the procedure to fix Bs for Tubel is shown in Fig. 14 in terms of flowchart and is found as 1.93:

$$
\begin{aligned}
& \quad{ }^{1}=\mathrm{T}_{\mathrm{ph}} \mathrm{i}=\mathrm{R}_{\mathrm{L}} \varnothing+\left(\mathrm{R}_{2} \varnothing\right) / 2=2\left(\mathrm{H}_{\mathrm{s}} 1 \mathrm{~s}\right) \\
& +\left(\mathrm{B}_{\mathrm{s}} \mathrm{A}_{1 \mathrm{~s}}\right) / \mathrm{P}_{1}+\left(\mathrm{H}_{\mathrm{rc}} \mathrm{l}_{\mathrm{rc}}\right) / 2+\left(\mathrm{H}_{\mathrm{y}} \mathrm{l}_{\mathrm{y}}\right) / 2
\end{aligned}
$$

Using the above steps the flux linkages values for the other Tubes have been found and are shown in Table 3.

The total unaligned inductance $(\mathrm{Lu})$ is $1.98 \mathrm{mH}$. The values of flux linkage for different values of current ranging from $0 \mathrm{~A}$ to $15 \mathrm{~A}$, are given in Table 4

The aligned work done is given by the area under curve 1 and unaligned work done is given by the area under curve 2, as shown in the Fig. 15.

The total work done $\mathrm{W}$ is given by the difference in the area under curve 1 and curve 2 as given by equation. (11). Work done at aligned and unaligned positions are given by Eq. 12-13 respectively:

$\mathrm{W}=\mathrm{W}_{\text {aligned }}-\mathrm{W}_{\text {unaligned }}$

$\mathrm{W}_{\text {aligned }}=\alpha \times\left(\mu_{1}+\mu_{2}+\mu_{3}+\mu_{4} \ldots+\mu_{14}\right)$

$+\left(\mu_{15} \times(\alpha / 2)\right)$

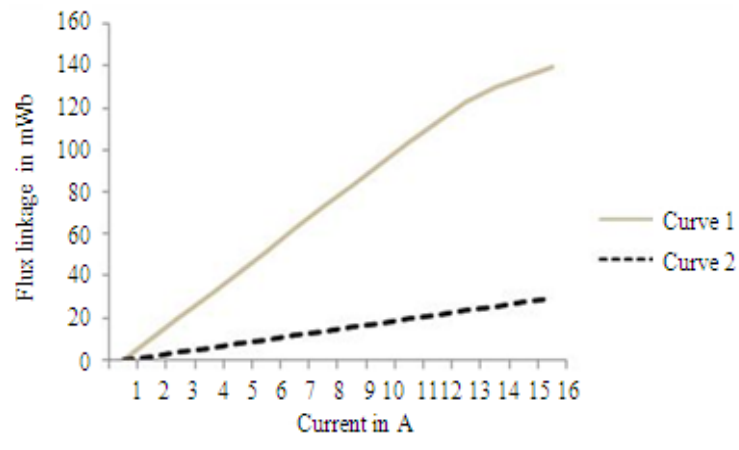

Fig. 15: Flux linkage characteristic

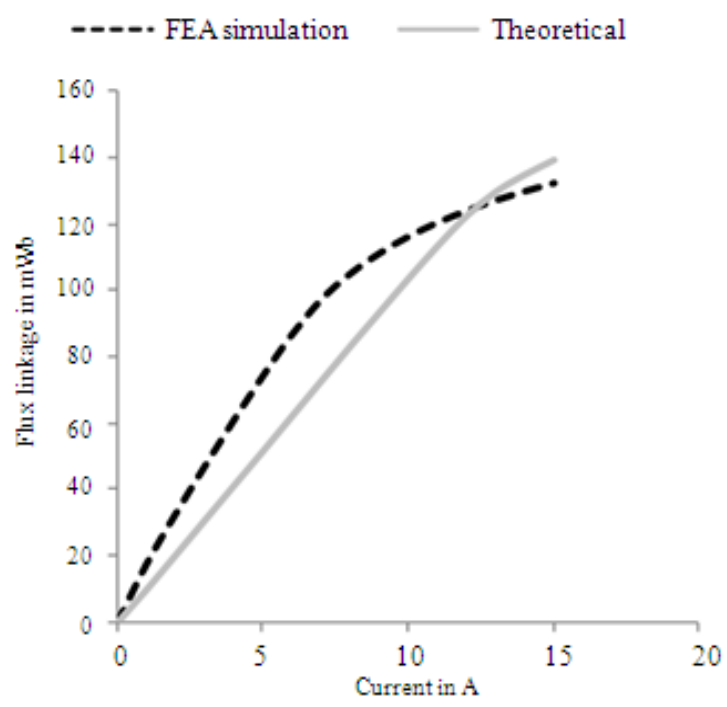

Fig. 16: Aligned flux linkage

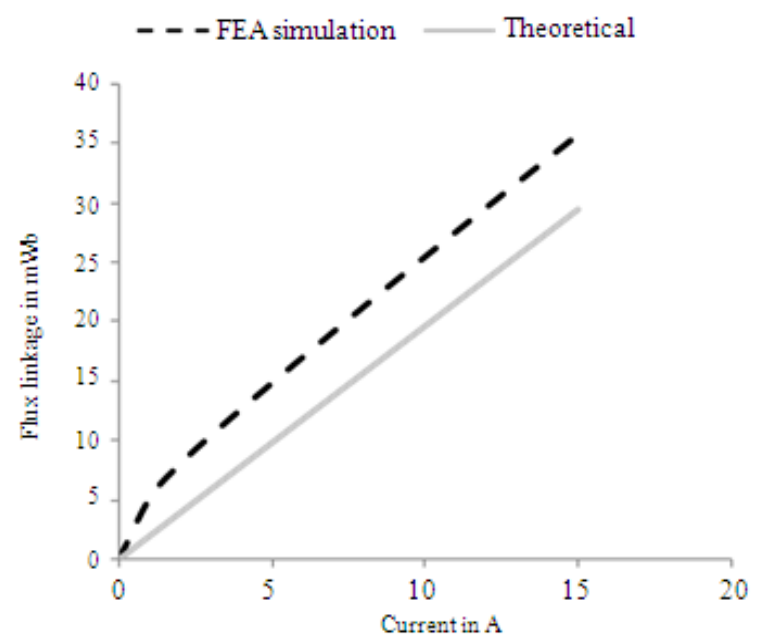

Fig. 17: Unaligned flux linkages 


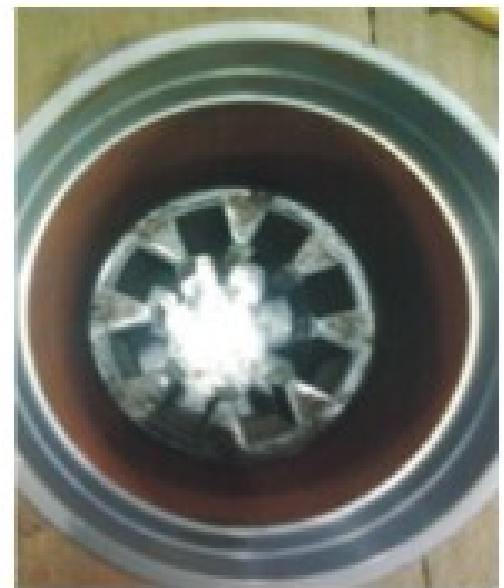

Fig. 18: Stator core

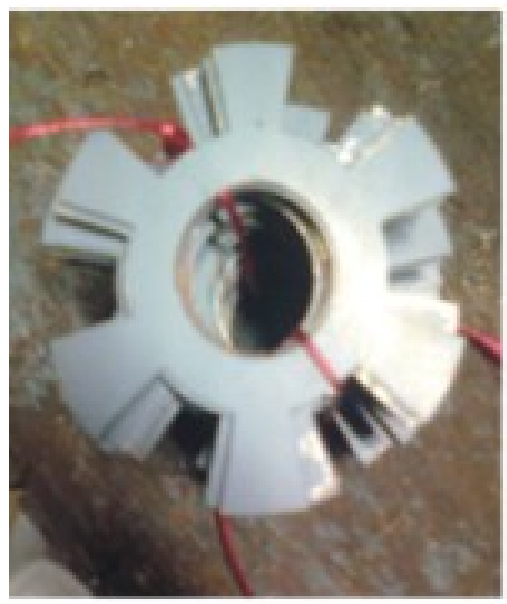

Fig. 19: Rotor stamping

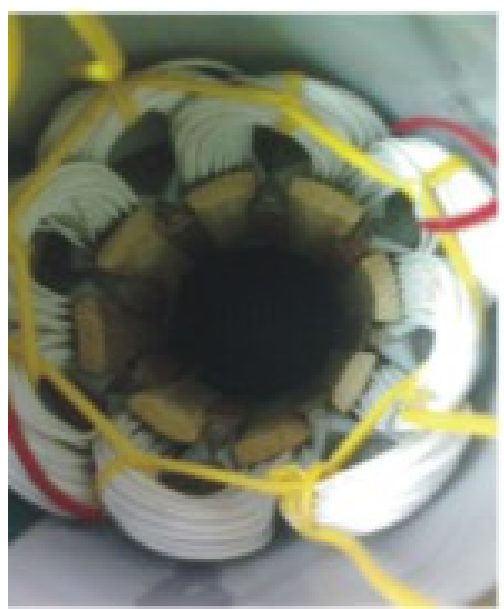

Fig. 20: Stator core with winding

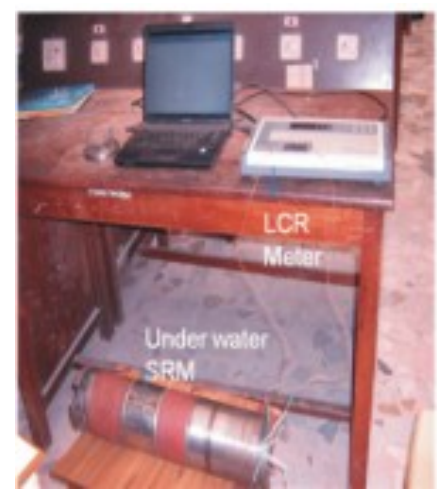

Fig 21: Inductance measurement setup

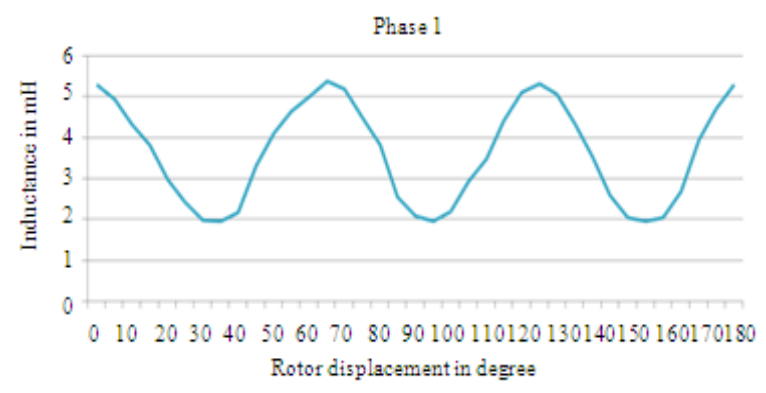

Fig. 22: Inductance profile of one phase

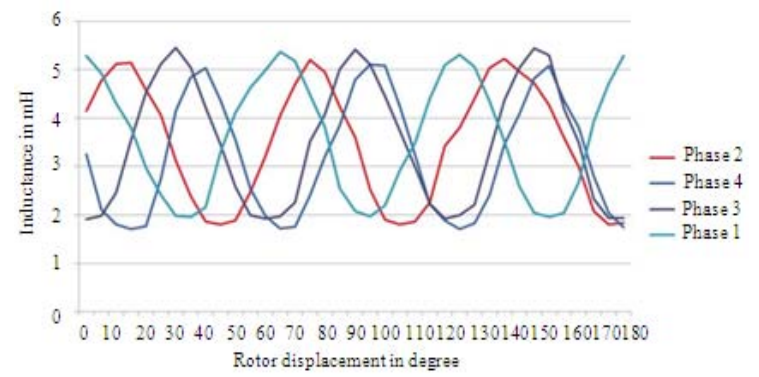

Fig. 23: Inductance profile of all phases

where $\mu$ is the flux linkage $\mathrm{W}_{\text {aligned }}=1.138$

$\mathrm{W}_{\text {unaligned }}=(1 / 2) \mathrm{L}_{\mathrm{u}} \mathrm{i}_{\mathrm{p}} 2$

Wunaligned $=0.222 \mathrm{~J}$

$\mathrm{W}=0.915$

The average torque is given by Eq. (14).

$\mathrm{T}=(\mathrm{WNsNr}) / 4 \pi$ 
where, $\mathrm{N}_{\mathrm{s}}$ and $\mathrm{N}_{\mathrm{r}}$ are number of stator and rotor poles respectively and the torque is found as $\mathrm{T}=3.5 \mathrm{Nm}$.

The values of flux linkages at aligned and unaligned positions, calculated theoretically are compared with those values obtained through Finite Element Analysis (FEA) in ANSYS. Figure 16-17 show the plot of flux linkage versus current obtained through FEA and theoretical calculations for both aligned and unaligned positions, respectively.

Real time verification of the machine and its inductance measurement set up: The stator core is shown in Fig. 18-20 show rotor stamping and stator core after winding. Figure 21 shows the measurement setup of inductance over various rotor positions with LCR meter. The variation of inductance with different rotor positions is measured using LCR meter and has been plotted for one of the four phases and is matching with the general inductance profile of SRM. This profile is shown in Fig. 22-23.

\section{DISCUSSION}

Flux linkage characteristics are calculated by using a simple MATLAB and ANSYS FEA Method. The aligned value is $132.45 \mathrm{mWb}$ and $139.3 \mathrm{mWb}$ respectively for the current $15 \mathrm{~A}$. The Unaligned value is $35.801 \mathrm{mWb}$ and $29.55 \mathrm{mWb}$ respectively for the current 15 A. After constructing the motor, the inductance profile was measured for all individual four phases. It is seen that all four phases are equal aligned and unaligned inductance value of $5 \mathrm{mH}$ and $2 \mathrm{mH}$. The MATLAB program can be used for all other Submersible SRM Motor ratings to predetermine the flux linkage characteristics.

\section{CONCLUSION}

In this study, a simplified method for the determination of flux linkage characteristics of submersible SRM using MATLAB has been presented. The obtained value has been validated with the ANSYS FEM method. It is found from Fig 4 and Fig 7 that the calculated unaligned and aligned inductance values of a 4-phase, $3 \mathrm{hp}, 220 \mathrm{~V}$ Submersible SRM using simplified MATLAB method very much matches with the ANSYS FEM Method. The small variations between the two methods can be further minimized by properly defining a library of materials that composes the object (or project) being modelled, which includes thermal and mechanical properties. In this study the ANSYS FEM analysis has been made for the M47 steel grade.

\section{REFERENCES}

Cai, Y., Q. Yang, L. Su, Y. Wen and Y. You, 2010. Nonlinear modeling for switched reluctance motor by measuring flux linkage curves. Proceeding of the 2nd International Conference on Computer Engineering and Technology, Apr. 16-18, Tianjin, China, pp: 47-51. DOI: 10.1109/ICCET.2010.5486289

Afjei, E., A. Seyadatan and H. Torkaman, 2009. A new two phase bidirectional hybrid switched reluctance motor/field-assisted generator, J. Applied Sci., 9: 765-770. ISSN: 1812-5654

Lu, K., P.O. Rasmussen and A.E. Ritchie, 2009. Investigation of flux-linkage profile measurement methods for switched-reluctance motors and permanent-magnet motors. IEEE Trans. Instru. Measur., $\quad 58$ : 3191-3198. $\quad$ DOI: 10.1109/TIM.2009.2017154

Santos, S.P.Y., E. Delbone, E.F. Carvalho and L.N. Martins, 2010. Synchronous generator disturbance provoked by induction motor starting. Am. J. Applied Sci., 7: 962-968. DOI: 10.3844/ajassp.2010.962.968

Souiyah, M., A. Muchtar, A. Alshoaibi and A.K. Ariffin, 2009. Finite element analysis of the crack propagation for solid materials. Am. J. Applied Sci., 6: 1396-1402. DOI: 10.3844/ajassp.2009.1396.1402

Sundaram, M., P. Navaneethan and M. Vasanthakumar, 2009. Magnetic analysis and comparison of switched reluctance motors with different stator pole shapes using a 3D finite element method. ICGST-ACSE J., 9: 49-53. ISSN: 1687-4811

Ustun, O., 2009. Measurement and real-time modeling of inductance and flux linkage in switched reluctance motors. IEEE Trans. Magnetics, 45: 5376-5382. DOI: 10.1109/TMAG.2009.2026897 